\title{
The impact of electronic monitoring and disruptive innovation on recidivism rates in federal prisons: a secondary data analysis
}

\begin{abstract}
A growing body of evidence shows that electronically monitoring offenders is effective for reducing the costs of overcrowded prisons. However, the effectiveness of electronic monitoring technology to reduce recidivism is poorly understood. The aim of this investigation is to assess the relationships between recidivism rates and electronically monitoring offenders using a secondary data analysis. The analysis conducted and was aimed to answer the following questions: Is there any relation between electronic monitoring devices and reducing recidivism rates among offenders? Is there any relation between technological advances of electronic monitoring on recidivism? Are the technological advances of electronic monitoring devices a form of disruptive innovation in government? Aggregate data sets from the Florida Department of Corrections Bureau of Research and Data Analysis Community Supervision section were used to generate quantitative data to analyze the associations between recidivism rates and electronically monitoring offenders from 2005 through 2007. With aggregate data, associations can be measured among groups of offenders sentenced with and without electronic monitoring and comparing other group information on a risk factor with the recidivism rate as an outcome. As a result, the outcomes of this research showed:

a. That electronically monitoring offenders does not significantly reduce recidivism and

b. Electronic monitoring technology is an example of disruptive innovation in government.
\end{abstract}

Keywords: recidivism, disruptive innovation, electronic monitoring
Volume 5 Issue 4 - 2017

\section{Woosong Reagan JR}

Woosong University, South Korea

Correspondence: Reagan JR, Woosong University, South Korea, Email jr.reagan ! @gmail.com

Received: March 08, 2017 | Published: March 31, 2017

\section{Overview and objectives}

This pilot research study evaluated the impact of electronic monitoring tracking devices used by correctional agencies in the states of Florida to monitor offenders on community supervision. This work is designed to yield data to measure recidivism rates among offenders placed on community supervision with and without electronic monitoring, and how technological advances of electronic monitoring devices illustrate disruptive innovation in government.

\section{Specific aims and hypotheses}

The efforts to reduce overcrowding in jails and prisons and reduce recidivism now involve community corrections programs with electronic monitoring devices. The use of electronic monitoring is now favored in many states correctional system because of its cost-effectiveness and practical solution to incarceration. Although correctional departments have shown a reduction in costs by electronically monitoring offenders on community control, few data exist to document its efficacy of reducing recidivism. This research study evaluated the effectiveness of electronically monitoring offenders in the state of Florida. While yielding data to measure recidivism rates among offenders placed on community control, the study also illustrates how electronic monitoring technology is an example of disruptive innovation in federal prisons.

\section{Specific Aims}

i. Conduct a comprehensive literature search for relevant published articles and studies on recidivism rates, technological advances of electronic monitoring and examples of disruptive innovation in government. Sources for finding articles included electronic databases; review of bibliographies of relevant published articles, government and nongovernment reports. Review the literature thoroughly on recidivism, electronic monitoring and disruptive innovation in government.

ii. Design a case-control study and define a sample from the prison population as cases and controls using predictor variables and outcome variables that pertain to recidivism rates, electronic monitoring spending and cost per prisoner.

iii. Identify database(s) that include the chosen predictor and outcome variables and review and become familiar with the databases from the Florida Department of Corrections and the Bureau of Justice Statistics [1] (FDOC). http://www.dc.state. fl.us/pub/spop/index.html

iv. Use the Florida Department of Corrections data sets for the pilot study [2]. http://www.dc.state.fl.us/pub/spop/index.html

v. Collect data from FDOC on recidivism outcomes of untreated 
offenders (offenders not monitored by EM) released from prison in 2005 and follow them through 2007. Collect data on Electronic Monitoring spending by U.S. prisons in 2005 and 2007/Collect data on cost per prisoner by U.S. prisons in 2005 and 2007. Use the data to formulate a specific hypothesis and settle on statistical methods.

vi. Analyze the data to measure recidivism rates of offenders monitored by EM with a control group of offenders not monitored by EM; Cost-benefits analysis of Electronic Monitoring spending between 2005 and 2007; Calculate cost per prisoner by Florida federal prisons between 2005 and 2007 .

\section{Background and significance}

Federal prisons have experienced an unprecedented increase in the number of incarcerated offenders for the past two and a half decades. There was an 80 percent increase in the prison population from 1990 to $2000 .^{3}$ In 2008, an all time high number of 2.3 million people were behind bars. The well-intentioned tougher sentences of "three strikes" laws, and "mandatory minimums," have increased the number of offenders incarcerated in the Florida prisons. The high costs of incarceration now trump higher education costs in some states. ${ }^{4}$ The Pew Research Center estimates the nation's yearly cost of incarceration to be about 50 billion dollars. The more offenders in prison the more money the state has to pay to house, supervise and rehabilitate them each year. The costs of incarceration come out of the state's primary pool of discretionary dollars. This means for every dollar spent on incarceration, less money is spent on education and social services. The money to pay for all of these services comes out of the same general discretionary fund.

Florida prisons have been charged by the state to reduce correction costs. "Florida law permits the court to order electronic monitoring for any convicted offender who is placed on probation or community control or as post-release supervision" (The Florida Senate 2011). Pew Charitable Trusts (2009) estimates the average daily cost of incarcerating a federal prisoner in 2008 was $\$ 78.95$. Schmitt, Warner \& Gupta's research (2010) shows the cost of a community surveillance program without electronic monitoring is about $\$ 3$ to $\$ 10$ per day. Klein-Saffran's research ${ }^{5}$ shows the cost of community surveillance with electronic monitoring is approximately $\$ 13.50$ per day. Electronically monitoring offenders would relieve the state of a huge financial burden. The Florida Department of Corrections published the 1995-1996 annual report which showed the age group of 18 to 24 years old comprised the largest percentage of offenders released on community control. The most common types of offenses among this age group are violence and drugs. About 35 percent of these offenders were placed on community control without electronic monitoring, 36 percent of them were placed on Radio Frequency (RF) electronic monitoring, and 29 percent of them were placed on Global Positioning Satellite (GPS) electronic monitoring. Offenders under the age of 18 and over 40 had the smallest number of placements in all three programs. The 2004-2005 annual report showed similar results for this age group. However, sexual offenders comprise the largest group for being placed on Global Positioning Satellite (GPS) electronic monitoring, about 29 percent according to the Florida Department of Corrections. ${ }^{6}$

\section{Electronic monitoring history}

Electronic tracking devices date back to 1919 to track cargo being transported to other states and overseas, but not for tracking humans. The idea of using electronic monitoring to track humans began in 1964 by Ralph Schwitzgel, in particular to monitor offenders. It was first implemented by the Department of Corrections in the 1980's. ${ }^{5}$ A federal prison in Palm Beach County, Florida began using Radio Frequency (RF) in 1984 to monitor offenders under house arrest. Offenders wear a small transmitter that communicates by radio signals. The cost to monitor an offender using radio frequency devices is about $\$ 1.97$ per day (Florida Senate, 2011). Another type of device that uses radio signals is the Global Positioning System (GPS). Offenders wear an ankle bracelet that contains the GPS monitoring system. The passive and active GPS systems were used on offenders from 2003 to 2006. The cost to monitor an offender with a GPS device is about $\$ 4.00$ per day. Monitoring offenders electronically has increased dramatically since 1980 . This method of monitoring has saved the states millions of dollars each year. The 2006 report by the Florida Department of Corrections shows radio frequency monitoring was used from 1993 to 1998. From 1999 to 2006 the placement pendulum swung from radio frequency to global position monitoring (GPS). A report by Klein-Saffran ${ }^{5}$ states it costs $\$ 13.50$ per day to put a Federal offender on an electronic monitoring program. Pew Charitable Trusts (2009) estimates the average daily cost of incarcerating a prisoner in 2008 was $\$ 78.95$. That means a savings of $\$ 65.45$ per prisoner per day. The question is how accurate and reliable are these devices and how effective is electronic monitoring for reducing recidivism?

\section{Recidivism}

The criminal justice community defines recidivism as criminal behavior after being convicted, punished, rehabilitated and released. In other words, repeat offenders are known as recidivists. Another term used for criminal recidivism is habitual offenders. Someone who has committed two or more felonies or numerous misdemeanors will be labeled as a habitual offender. Recidivism is short for repeated or habitual criminal behavior. The increased prevalence of recidivism reflects the increased number of people in prisons, therefore recidivism is proportionate to increased prison population. A national recidivism study published in 1983 and 1984 tracked release prisoners in 15 states for three years. The findings from this study showed twothirds of those prisoners released in the U.S. were rearrested and reincarcerated for new crimes within three years. Recidivism rate was up by 5 percent since the prior national study in 1983. Offenders with the highest re-arrest rates are robbery, violence, burglary, drugs and weapons offenses. Prisoners with the lowest re-arrest rates are sexual and murder offenses. However these offenses are treated much differently than other types of offenses and they make-up a small percentage of the prison population. The ocer all findings of the study showed 30 percent of offedners released from prison were reincarcerated within six months, 44 percent reincarcerated within a year, 59 percent within two years, and 67 percent near the end of three years. ${ }^{7}$ The Bureau of Justice Statustics reports that 16 percent of one million prisoners nationwide released on parole supervision in 2007 were reincarcerated during that same year. What we don't know is how many of those offenders were monitored electronically and those that were electronicaly monitored what was the cause for recidivism. 


\section{Disruptive innovation}

Disruptive innovation is defined as innovation that is highly revolutionary or discontinuous nature, in which customers embrace new paradigms in favor of the old. ${ }^{8}$ Instead of sustaining or making incremental improvements to existing technologies, disruptive innovation applies new technologies, or combinations of technologies, to market new opportunities, ${ }^{9}$ that produce new products, services or business models. These innovations bring different value propositions to new market contexts that did not need all the performance offered by incumbents ${ }^{8}$ After taking root in a simple, undemanding applications, disruptive innovations inexorably gets better until they "change the game" (Gharajedaghi 1999), displacing established incumbent organizations. Ahuja and Lampert ${ }^{10}$ have expanded on those ideas by showing how technological breakthroughs can lead to potentially disruptive innovations and how it can be developed though exploring: 'novel technologies', 'emerging technologies', and, 'pioneering technologies'. Disruptive innovation is prevalent in industry and some areas of government such as education, healthcare, and social services. Disruptive innovation has not been addressed in the US Department of Justice though it clearly exists. A prime example of electronic monitoring and disruptive innovation in prisons is in Rock County jail in Florida. Rock County had plans to build a 56 million dollar extension to the overpopulated county jail. Their plans were cancelled when electronic monitoring program led to a significant decline in the prison population and the occupancy fell far below capacity and saved the county 56 million dollars. ${ }^{11}$ Wood ${ }^{11}$ indicates that these innovative technologies force the criminal "to monitor himself....effectively outsourcing the role of prison guard to prisoners themselves". How did the introduction of low-cost monitoring device technology disrupt the traditional incumbent role of the U.S. prison system?

Community Control I is a form of intensive supervised custody in the community, including surveillance on weekends and holidays, administered by officers with limited caseloads. It is an individualized program in which the freedom of the offender is restricted within the community, home or non-institutional residential placement, and specified sanctions are imposed and enforced. As with probation, violation of any community control condition may result in revocation by the court and imposition of any sentence which it might have imposed before placing the offender on community control supervision. Many of the offenders who are placed on community control are prison diversions. Community Control II uses electronic monitoring as an enhancement to community control and continues to receive judicial approval. Electronic monitoring exists in all twenty (20) judicial circuits in the state of Florida. These units are monitored on a 24 hour a day basis by private vendors who immediately report all violations to probation staff for further investigation. So the question is whether delivering less to more people through community control II is just as effective as community control I. What are the tradeoffs in terms of quality of community supervision and recidivism rates. The main objectives for finding ways to ease overcrowding in prisons and reduce recidivism are driven by economic and political pressures. The innovation of electronically monitoring offenders might turn out to be an inferior way of reducing recidivism and may even compromise the safety of the community. The electronic monitoring system is an example of disruptive innovation in government by delivering less direct community supervision and rehabilitation services to more offenders. ${ }^{12}$
This pilot study also evaluated electronic monitoring technology subject to disruptive innovation. For the purpose of this study, disruptive technologies are defined as technologies that enable a product to have features suitable for new business models but leads to disruptive innovation as described by Tellis. ${ }^{13}$

New technology initially underperforms the dominant one along the dimensions mainstream customers in major markets have historically valued.

Has new technology has other technical performances that new or non-consumption customers' value.

Products based on disruptive technology are typically cheaper, simpler, smaller, or more convenient than those established on dominant technology.

\section{Methods}

\section{Overview of design}

The objectives of this study is to

a. Identify prisons that use electronic tracking devices to monitor low-level offenders and collect data on recidivism and type(s) of electronic tracking devices used;

b. Evaluate and compare the use of electronic monitoring devices with traditional release programs and

c. Evaluate the hypotheses that electronic monitoring technology is an example of disruptive innovation in government and the tracking devices do not manifest a significant reduction in recidivism.

The specific aims of this study are pursued through a secondary data analysis using aggregate data sets. With aggregate data, associations can only be measured among these groups by comparing group information on a risk factor with the rate of an outcome. The advantage of aggregate data is its availability. The major drawback is the fact that associations are especially susceptible to confounding variables. Groups tend to differ from each other in many ways, not all of which are causally related. Furthermore associations observed in the aggregate do not necessarily hold true for the individual. Aggregate data will be used to test the plausibility of new hypotheses.

\section{Data collection}

Aggregate datasets from the Florida Department of Corrections (FDOC) were used to determine the impact of electronically monitoring offenders and recidivism. The Florida Department of Correction's Offender Based Information System (OBIS) is a data management system of offenders under its jurisdiction. The aggregate data provided group information about community control for offenders from year 2005 through year 2007 with and without electronic monitoring. Florida Department of Corrections authorities use this data to monitor and document activities of offenders on community control. To measure recidivism and account for effects of factors known to influence recidivism rates, the FDOC data contains information about type of offenses, sentencing and monitoring. Releases subsequent to a return to prison for technical violation of supervision conditions are not treated as additional releases, because this would artificially lower the recidivism rate. 


\section{Measurements}

Secondary data analysis was used to answer the following research questions:

1) Was there any relation between electronic monitoring devices and recidivism among low-level offenders?

2) Was there any relation between technological advances of electronic monitoring on recidivism among low-level offenders?

3) Are the technological advances of electronic monitoring devices a form of disruptive innovation in government?

\section{Results \& conclusion}

Research results showed the following:

i. Electronic monitoring does not significantly reduce recidivism; and

ii. Electronic monitoring technology is an example of disruptive innovation in government.

The results from this study can be pursued in additional studies using individual data to study whether electronic monitoring devices reduce rate of crime if a prisoner is released from prison and being watched by any one of the electronic monitoring system. In order to study this we need the data corresponding to the number of prisoners under EM each month and the number of offenders arrested after committing another crime.

The data corresponding to number of offenders arrested during each month of the period was split into two,

a. Original/new offenders and

b. Offenders under post prison.

Our aim of study led to the fact that offenders under post prison falls under electronic monitoring/another monitoring devices, under the assumption that they are arrested earlier for another crime and send outside the prison with proper monitoring system, being low level offenders/or reduce the cost of keeping them inside the prison.

Offenders under EM were divided into three, Probation, Community Control and Post prison. From this sub division it is clear that offenders under post prison are monitored by more than one device. Since the number of offenders released under EM corresponding to each month/time period not available, a statistical study is difficult to test whether EM is a good tool for reducing recidivism. From the available data and considering the assumptions given above, the possible conclusion is:

i. From January 2005 to December 2007, only $0.72 \%$ of total prisoners were arrested under EM.

ii. In the same period, $20.11 \%$ of prisoners in post prison were arrested under EM and $2.15 \%$ of offenders in post prison category were arrested under the post prison category in EM.

If all the offenders released from prison were monitored by any one of the electronic monitoring device, then it was possible to conclude that EM was a good tool for controlling repeated crime. (Only 2.15\% fall under this category compared to $20.11 \%$ under post prison). i. Using regression analysis, I selected the number of prisoners under 'post prison' in the group of total prisoners as independent variable y and number of offenders arrested under 'post prison' of electronic monitoring as depended variable $\mathrm{x}$, to do the study .

ii. Consolidating the data for 3 years, the regression lines are $\mathrm{Y}=1.54 \mathrm{x}+5168$ and $\mathrm{x}=.003957 \mathrm{y}+94$.

iii. The correlation between the number of offenders under 'post prison' category and the number of offenders arrested using EM under the 'post prison' category is 0.60307 . They are positively correlated, that means increase in one quantity increases the other and vice versa. The use of electronic monitoring device to monitor prisoners outside the prison is effective but it doesn't mean that recidivism rate reduced by using electronic monitoring.

The finding that many offenders report electronic monitoring to does not significantly deter criminal behavior is unquestionably noteworthy. However, establishment for the veracity of these selfproclaimed reports that truly reduce criminal conduct has to be done. Results of outcome evaluations have are limited by the methods they utilize, making any firm conclusions regarding their merits difficult to ascertain. Differences in outcome indices examined, risk levels of offenders included, supervision regimes and incorporation of program components, also create multi-studies comparisons difficult, thus having equal importance in defining the relative "success" of EM programs. Recidivism and release violations could also be reviewed to determine commonly addressed outcome measures.

\section{Potential problems/biases}

The empirical assessment of the effect of EM on offender outcomes was limited to medium- and high-risk offenders, which we were able to distinguish from low-risk offenders based upon FDOC's risk classification in OBIS. Two groups of offenders were identified, first, those placed on EM at some point in their community supervision (the EM or "treatment" group), and second those offenders who were supervised without the use EM technologies (non-EM or "control" group). The data has three limitations, none of which should impair their use in this study. First, some inmates released from prison in Florida who commit subsequent felonies are sentenced to local jails rather than returned to the FDOC's jurisdiction. $\mathrm{FDOC}^{6}$ estimates that including jail data would raise reoffense rate estimates by only 1.2 to 1.6 points at three years after release. Second, inmates released out-of-state are excluded. Based on an analysis by the Bureau of Justice Statistics (Langan and Levin, 2002), FDOC estimates that including out-of-state releases would raise re-offense rate estimates by 0.85 to 1.3 points at five years after release. Third, inmates who die subsequent to release are not excluded from the analysis, but excluding them would have a negligible effect on rate estimates according to FDOC. The only way these data limitations could bias results from this analysis is if the likelihood of jail sentences for new offenses, outof-state releases and reconvictions, or post-prison death are different for public and private prison inmates. It is not anticipated that these factors should not differ between the monitoring and comparison groups analyzed for this study.

To ensure that offenders in the control group were similar to those in the monitoring group, the population for this study consisted only of prisoners released since 2002, as valid and reliable EM monitoring 
data were not available prior to this period. The population from which the monitoring and comparison groups were drawn includes only offenders who were admitted to prison after December 31, 2001. As a result, this study does not include offenders with longer sentences who were directed to EM monitoring. Still, the study captured the vast majority of offenders released in 2005 who were directed to EM monitoring given that only percent of the releasees from 2005 were admitted to prison prior to 2002 .

Early reviews of empirically-based outcome evaluations that have used recidivism rates as the criterion interest generally suggest that offenders who are electronically monitored have the same or similar conditions to offenders sentenced to more restrictive sanctions. ${ }^{14}$

Nonetheless, it is generally conceded that this conclusion is tentative at best given that most of the initial evaluations suffered from several methodological limitations, with particular reference being made to low-risk volunteer's reliance, small sample sizes, and use of random assignment failure. ${ }^{14}$ Results that contradict with each other may have been the result in the varying definitions of recidivism. ${ }^{14,15}$ Unfortunately, early evaluations methodological problems also characterize outcome studies nearly 20 years after the implementation of EM programs (Bonta et al., ${ }^{16}$ ) findings from researches that sought to address these problems are discouraging. In the widely cited Canadian study by Bonta et al., ${ }^{17}$ for example, the authors found that once risk level was taken into consideration, EM offenders no longer showed significant difference in recidivism rates compared to groups of offenders who were on probation EM and those released directly into the community with no such conditions imposed.

It can be noted that on examination of recent literature reviews on the effectiveness of EM on recidivism for different levels of risk offenders, EM practices do not hold any potential merit in improving outcomes. However, a majority of these summaries contain errors. An example of such error is Renzema and Mayo-Wilson's ${ }^{18}$ review which illustrates the process by using a flowchart of which a reduction of 154 outcome evaluations to only three that reached their criteria for inclusion. The researchers concluded that EM's effect on recidivism has little impact. The conclusion of EM's impact on recidivism as having little impact warrants skepticism since a broad conclusion is based on only three literature which are characterized with results that show either mixed or inconclusive ${ }^{19,20}$ examined the effects of various intermediate sanctions on recidivism. However only six studies were involved in this meta-analysis and the aggregate rates of recidivism are reported. According to their study, EM programs have minimal effect on re-offending based on the comparison between the $6 \%$ recidivism rate for EM offenders and the 4\% rate for the comparison group. Although the conclusion of these studies may be valid, it is too broad to generalize since there are only a few studies involved and there is limited to small sample size of 1,414 offenders.

Other larger scale evaluations compared to the aforementioned studies provide positive results that are concerned with the impact of EM in re-offending reduction. A report was issed on October 2003 by the state of Florida on the impact of EM across varied outcome measures that include recidivism, revocation, and absconding. ${ }^{6}$ The research covered a ten-year period commencing from July 1993 and ending on June 2003 that involved 63,000 cases which had a controlled background factors that include current offence type, sentence length, prior convictions, violations, and demographic characteristics. Evaluation of outcomes was followed-up in a two-year period. The report concluded that when comparing offenders who participated in the EM program to those offenders under community supervision who were without EM supervision, the latter were more likely to be commit a new crime (i.e. $2.8 \%$ vs. $9.8 \%$, respectively), have a doubled possibility of committing a new offense (i.3. $1.3 \%$ vs $3.5 \%$ ), and more than thrice to commit absconding (i.e. $7.0 \%$ vs. $16.1 \%$ ). Furthermore, offenders who were not under the EM program double the possibility of revocation of their release for any type offence compared to those under EM supervision. In another study of Padgett et al., ${ }^{9}$ positive results across comparable outcome indices were obtained from a Florida-Based study of a five-year cohort of 75,661 serious offenders placed on home confinement. GPS technology's incremental value relative to RF equipment was also examined in this study. The reduction of the likelihood of revocation for a new offence and absconding from supervision were significantly reduced by both monitoring systems. The use of GPS monitoring's enhanced surveillance capabilities and RF monitoring had the same deterring effect across diverse groups of offenders (i.e. property, violent, and drug offenders) in terms of reduction of revocations and of absconding incidents. The results of these studies emphasize that there is significant inbiting effect on offending behavior for diverse groups of offenders with the use of EM technology. However, the study is delimited to whether these inhibiting qualities are influenced by the duration of the monitoring period and effects to long-term changes in behavior. Public safety is enhanced when EM is being used. Furthermore, the study recommends the conduct of future researches that address EM's long term viability as a tool for rehabilitation. In addition to this outcome evaluation, it is also recommended that there will be a comparison of the relative efficacy of GPS technology compared to other types of monitoring in terms of the effect of re-offending.

European countries and the United States focus their efforts in EM programs. Scientific studies made on EM in Sweden, England, Netherlands, and Belgium show positive results in terms of the effectivity of EM technology in reduction of re-offending and compliance with release conditions (Boelens, Jonsson, \& Whitfield, 2003). Studies that target high-risk offenders show successful program completion rates of as high as $80 \%$ to $90 \%$ in many cases. EM programs all over Europe have suggested that these have significant effect in improving community supervision practices in working with individuals that are considered high-risk offenders. Contradictory results are produced in the review of different researches that focus on the effectiveness of EM in reducing recidivism rates. Although EM programs have been used for approximately two decades, it is only of recent times that evaluations of the results of such programs come out. Recent studies on the probability to re-offend on low-risk offenders have been made whether they are under the EM programs or not. Moreover, most studies conclude that it is not the EM programs that have brought positive effects but on the risk level of offenders. ${ }^{16}$

On the other hand, other studies result to positive results that have included high-risk offenders based on larger sample sizes, 'enhanced methodological rigor, and superior data analytic techniques'. ${ }^{19}$ Although most studies do not conclude that EM has a significant effect on reduction of recidivism rates, it is not correct to say that EM programs have no role. EM's surveillance capabilities which are beyond traditional human monitoring practices increase trust in the system for public safety and security. Furthermore, offenders in the rehabilitation process would be highly motivated to join EM's programs which could result to achieving long-term behavioral change. ${ }^{21,22}$ 


\section{Moving forward: recommendations for advancing EM practices}

Outcomes of this study should also help identify questions fo future research. This research should provide insight into the use of Disruptive Innovation in Government through the examination of Electronic Monitoring on the U.S. prison system. Until there are conclusive studies that merit the effectiveness of electronic monitoring programs, there will be continued gray areas in the true reduction of recidivism rates. Various issues need to be addressed that are of importance. It is suggested that comparisons among different levels of offenders be conducted with both radio frequency and global positioning system devices and there should be further exploration between successful completions of programs employed. Surveys on how offenders perceive electronic monitoring programs, and the public's opinion on such practices in the criminal justice process should also be conducted. ${ }^{23-33}$

\section{Acknowledgement}

None.

\section{Conflict of interest}

None.

\section{References}

1. Bureau of justice statistics. Prisoner recidivism analysis tool. retrieved september 1, 2011, from Bureau of Justice Statistics. 2011.

2. Aizeman N. The high cost of incarceration. Retrieved from denverpost 2008.

3. Ring W. Vermont tops list of states spending more on prison than college. The PEW center on the states vermont USA associated press; 2010.

4. Klein-Saffran J. Electronic monitoring vs. halfway houses: a study of federal offenders. Alternatives to Incarceration. 1995;2-28.

5. Florida department of corrections. A controlled study of the effects of electronic monitoring and officer caseload on outcomes for clients in community control. flrodia department of corrections. Tallahassee Florida: Florida Bureau of Research and Data Analysis. 2003.

6. Langan PA, Levin DJ. Recidivism of Prisoners Released in 1994. United states department of justice, Office of Justice Programs; Bureau of Justice Statistics. Unites States Department of Justice. 2006.

7. Christensen CM, Rosenbloom R. Explaining the attacker's advantage: technological paradigms, organizational dynamics and the vaue network. Research Policy. 1995;24(2):233-257.

8. Tushman ML, Nadler D. Organizing for innovation. California Management Review. 1986;28(3):74-92.

9. Ahuja G, Lampert C. Entrepreneurship in the large corporation; longitudinal study of how establlished firsm create breakthrough inventions. Straetgic Management. 2001;22(6-7):521-543.

10. Wood G. Prison without walls. Atlantic Monthly. 2010;306(2):86-96.

11. The Stopped Clock Blogspot. The Stopped Clock. Retrieved September 112011 from Blogspot: The Stopped Clock. 2010.

12. Tellis G. Disruptive technology or visionary leadership. The Journal of Product Innovation Management. 2006;23(1):34-38.
13. Rogers R, Jolin A. Electronic monitoring; a review of the empirical literature. Journal of Contemporary Criminal Justice. 1989;5(3): 141153.

14. Petersilia J, Turner S. Comparing intensive and regular supervision for high risk probationers. Crime and Delinquency. 1990;36(1): 87-111.

15. Bonta J, Wallace-Capretta S, Rooney J. A quasi-experimental evaluation of an intensive rehabilitation supervision program. Criminal Justice nad Behavior. 2000;27(3):312-329.

16. Bonta J, Wallace-Capretta S, Rooney J. Can electronic monitoring make a difference? An evaluation of three Canadian programs. Crime and Deliquency. 46(1):61-75.

17. Renzema M, Mayo-Wilson E. Can electronic monitoring reduce crime for moderate to high-risk offenders? Journal of Experimental Criminology. 2005;1(2):215-237.

18. Padgett KG, Bales WD, Blomberg TG. Under surveillance; an empirical test of the effectiveness and consequences of electronic monitoring. Criminology and Public Policy. 2006;5(1):61-92.

19. Gendreau P, Goggin C, Cullen FT, et al. effects of community sanctions and incarceration on recidivism. Forum on Corrections Research. 2000;12:10-13.

20. Gable RK, Gable RS. Electronic monitorins; positive intervention strategies. Federal probation. 2005;69(1):1-7.

21. Hanson RK, Bussiere M. Predicting relapse; a meta-analysis of sexual offender recidivism studies. Journal of Consulting and Clinical Psychology. 1998;66(2):348-362.

22. Andrews DA, Zinger I, Hoge R, $\mathrm{t}$ al. Does correctional treatment work? A clinically relelvant and psychologically informed meta analysis. Criminology. 1990;28(3):369-404.

23. Christensen $\mathrm{C}$. The ongoing process of building a theory of disruption Journal of Product Innovation Management. 2006;23(1):39-55.

24. Daneels E. Technology considered; A critique and research agenda Product Innovation Management. 2004;21(4):246--258.

25. Dowden C, Andreews DA.What works for female offenders; a metaanalytic review. Crime and Deliquency. 1999;45(4):438-452.

26. Dowden C, Andrews DA. Effective correctional treatment and violent re-offending; a meta-analysis. Canadian Journal of Criminology. 2000;42:449-476.

27. Gendreau P, Little T, Goggin C. A meta-analysis of the predictors of adult offender recidivism: what works!. Criminology. 1996; 34(4):575-608.

28. Govindarajan V, Kopalle P. The usefulness of measuring disruptiveness of innovations; ex post inmaking ex ante predictions. Journal of Product Innovation Management. 2006;23(1):12-18.

29. Langan PA, Levin DJ. Recidivism of prisoners released in 1994. United States department of justice, Office of Justice Programs; bureau of justice statistics. Unites States Department of Justice. 2006.

30. Latimer J. A meta-analytic examination of youth delinquency, family treatment and recidivism. Canadian Journal of Criminology. 2001;43(2):237-253

31. Tushman MI, Anderson P. Technological discontinuities and organizational environments. Admiinistrative Science Quarterly. 1986; 31(3):439-465.

32. Whitehead JT, Lab SP. A meta-analysis of juvenile correctional treatment Journal of Research on Crime and Deliquency. 1989; 26(3):276-295. 